\title{
SISTEMA DE PRODUÇÃO CONVENCIONAL VERSUS SISTEMA DE PRODUÇÃO SUSTENTÁVEL
}

\section{Priscilla Moreira Curtis Peixoto ${ }^{1}$}

${ }^{1}$ Aluna de Pós-graduação em Agroecologia e Sustentabilidade, IFES, Alegre, Espírito Santo.

DOI: 10.47094/ICONNECA.2021/18

\begin{abstract}
RESUMO
O avanço do mundo moderno acarretou dois tipos de progresso: o científico e o tecnológico, que promoveram uma maior eficiência e, em consequência, rentabilidade às técnicas de produção agrícola. Porém, acarretou também o encargo do risco ambiental, impactando diretamente a degradação do meio ambiente, causando mudanças climáticas, extinção de determinadas espécies da fauna e esgotamento dos recursos naturais. Com isso, a propriedade rural transformou-se, ao mesmo tempo, mais produtiva e mais degradadora. Ponderar sobre o tema desenvolvimento, associado com o aumento da pressão feita pela sociedade sobre o meio, ocasionou o aumento da consciência sobre a problemática ambiental gerada por padrões de vida divergentes ao processo de regeneração do meio ambiente. Sendo assim, se evidencia a importância da adoção de medidas à proteção do meio ambiente, com efetivo cumprimento do papel socioambiental da propriedade, com o objetivo de restringir a utilização da propriedade rural dirigida somente à obtenção de lucro.
\end{abstract}

PALAVRAS-CHAVE: Sistemas agroflorestais. Agroecologia. Sustentabilidade.

ÁREA TEMÁTICA: Recuperação de áreas degradadas.

\section{INTRODUÇÃO}

Os sistemas de produção convencionais provocam diversos impactos ambientais e sociais e, consequentemente problemas como o aumento da emissão de gases do efeito estufa, aumento do desmatamento e da contaminação de solos e das águas. Uma alternativa que já se mostrou eficiente é a implantação de sistemas agroflorestais (SAFs) que como sistemas baseados no melhor aproveitamento da área, busca aumentar produzir alimentos conservando a sustentabilidade dos agroecossistemas (CANUTO, 2017; RIBASKI et al., 2001).

No Brasil, a agricultura seguiu caminhos que apareceram desde o período colonial em forma das plantações camponesas de maneira marginal, até a introdução dos colonos imigrantes e o aumento da produção de alimentos. Entretanto, foi com a modernização do campo nos anos 1960 - 1970 que as mudanças aconteceram de maneira mais significativa (FILHO et al., 2018). Com base numa visão histórica, das restrições socioeconômicas, institucionais e ecológicas do modelo de modernização 
agrícola que se chamou de euro-americano, da qual divulgação em escala mundial aconteceu especialmente a partir dos anos 60, no centro da chamada Revolução Verde. O que se tentava mostrar é que as atuais práticas agrícolas vistas como modernas não foram apenas, como era muito afirmado, a única resposta técnica possível ou a mais efetiva para expandir a produtividade e os rendimentos da terra, de forma a fazer face às necessidades impostas pelo aumento demográfico e pelo processo de urbanização (ROMEIRO, 1998).

Ao contrário disso, existem os SAFs que são considerados exemplos de uso de solos que dentro do aspecto ecológico, mais se harmonizam com ambientes naturais, como as florestas, e que, portanto, são considerados como uma grande alternativa de utilização sustentável do ecossistema tropical úmido, isto é, são sistemas de produção que consorciam espécies florestais com cultivos agrícolas e às vezes com a integração de animais também, na mesma área e numa sequência temporal (BANDY et al., 1994).

Nesse sentido, o objetivo do trabalho é fazer uma abordagem sobre a importância de se adotar técnicas sustentáveis a forma de produção, mostrando seus benefícios quando comparado aos impactos dos sistemas produtivos convencionais.

\section{METODOLOGIA}

O presente trabalho trata-se de uma breve revisão, com um panorama geral de conceitos sobre os impactos do modelo de sistema produtivo convencional, com relação aos ambientes naturais e sistemas agroecológicos. Para a elaboração do trabalho, utilizou-se artigos, livros e outros tipos de trabalhos encontrados nas bases de dados, Google Acadêmico e Periódicos Capes, que discorrem o tema como embasamento para a revisão de literatura, visando aumentar a discussão acerca dos sistemas integrados de produção e temas relacionados, como: Sistemas convencionais de cultivo $\mathrm{x}$ Sistemas mais sustentáveis, como SAFs, em paralelo com a Agroecologia.

\section{FUNDAMENTAÇÃO TEÓRICA}

Segundo Santos e Araújo (2014), o setor do agronegócio é de grande importância para o Brasil e a cada dia que passa se moderniza mais. Elas ainda destacam que a adoção de novas técnicas e aplicação de sofisticadas tecnologias para colheita e tratamento do produto, assim como o estabelecimento de sistemas de irrigação e normalização do solo, tem melhorado e elevado a produtividade. Para as autoras é justificável que seja assim, visto que o setor participa significativamente na composição do produto interno bruto (PIB) do país.

De acordo com Gazzoni (2013), a sustentabilidade do agronegócio brasileiro é obtida, principalmente através da conduta empresarial, da visão de negócio das cadeias produtivas e das políticas públicas de expansão de crédito e seguro agrícola. Nesta perspectiva, a aplicação de políticas 
públicas mais ativas possibilitaria a adoção e execução de alternativas sustentáveis como, por exemplo, a utilização de recursos florestais de modo consciente e o desenvolvimento de tecnologias para melhoria de vida (MILANEZ, 2009; NASCIMENTO, 2017; PORTO; SOARES, 2012).

Agricultores e pesquisadores de todo mundo têm se preocupado com a sustentabilidade e continuidade das atividades agrícolas e os sistemas agroflorestais (SAFs) têm sido apontados como alternativa viável para a diversificação da produção e o desenvolvimento econômico rural (SANTOS et al., 2000; BIJARPAS et al., 2015). Os Sistemas Agroflorestais (SAF) são uma metodologia de utilização da terra no qual espécies florestais e não florestais são plantadas simultaneamente com cultivos anuais ou perenes.

Sistemas agroflorestais buscam atingir o máximo de aproveitamento possível dos recursos locais com menores custos e o mínimo de intervenção para que não diminua a função e/ou estrutura do ecossistema (COGLIATTI, 2004). Esses sistemas produtivos possibilitam a recuperação de ambientes degradados, a produção diversificada de cultivos, e ainda criar serviços ambientais, como acréscimo de matéria orgânica no solo, conservação da biodiversidade e compõem importantes sistemas de sequestro de carbono $\left(\mathrm{CO}_{2}\right)$ da atmosfera (BOLFE; BATISTELLA; FERREIRA, 2011).

Nas últimas décadas a recuperação de áreas degradadas ampliou as atividades neste âmbito e, assim, aumentou a preocupação em recuperar e preservar a biodiversidade original da floresta. Isso em função de problemas cada vez mais comuns, associados a secas, erosões e perda de solo, enchentes, esgotamento de rios e nascentes, e muitos outras formas de impactos associadas à degradação do ecossistema original. Deve-se considerar ainda, como motivos para se recuperar a vegetação, além dos aspectos da estética e paisagística, turismo, fatores históricos, conservação de recursos hídricos, favorecimento do microclima, recuperação do potencial econômico - biodiversidade, plantas medicinais, madeireiras, ornamentais, frutíferas - e atendimento a exigências legais (ALMEIDA, 2016).

Visto que a agricultura exerce uma função fundamental no desenvolvimento da economia das sociedades, com impacto no crescimento econômico, na geração de renda das famílias e na segurança alimentar, é de extrema importância o fortalecimento de ações de comunicação rural, para que os agricultores se certifiquem das inúmeras oportunidades de associar práticas sustentáveis à produção e com orientações sobre o cuidado com suas áreas de produção (SILVA et al., 2019).

\section{CONSIDERAÇÕES FINAIS}

A busca por alternativas sustentáveis na produção agrícola é de grande importância e tem aumentado a cada vez mais. E nesse contexto surgem os sistemas agroflorestais (SAFs) que, além de alternativa para a economia, constituem uma ótima opção para a recuperação de áreas degradadas.

Os sistemas integrados como os SAFs promovem a recuperação de áreas degradadas, saturadas por práticas não conservacionistas, se assemelhando com uma floresta natural que busca 
melhorar aspectos abióticos e bióticos favorecendo a ciclagem de nutrientes e, logo, melhorar os mecanismos vitais das plantas. O cultivo de espécies agrícolas e florestais na mesma área beneficia o agricultor e o ambiente, equilibrando o agroecossistema com os processos ambientais e compõem um método importante para a agricultura familiar e na preservação dos recursos naturais minimizando a degradação do meio ambiente.

\section{PRINCIPAIS REFERÊNCIAS}

BANDY, D.; GARRITY, D. P.; SÁNCHEZ, P. El problema mundial de la agricultura de tala y quema. Agroforestería en las Américas, v. 1, n. 3, p. 14-20, 1994.

BIJARPAS, M. M.; SHAHRAJI, T. R.; LIMAEI, S. M. Socioeconomic evaluation of agroforestry systems (Case study: Northern Iran). Journal of Forest Science, v. 61, n. 11, p. 478-484, 2015.

BOLFE, E. L.; BATISTELlA, M.; FERREIRA, M. C. Correlação entre o carbono de Sistemas Agroflorestais e índices de vegetação. In: Simpósio Brasileiro De Sensoriamento Remoto, 15., 2011, Curitiba, PR. Anais [...] Curitiba: INPE, 2011.

FILHO, F. L. A.; HEINECK, J. A.; BENVENUTTI, N. Agricultura Familiar - uma história, um legado. In: Congresso Internacional de Educação do Sudoeste do Paraná: Desafios Contemporâneos, 3, 2018, Ampére, PR. Anais [...] Ampére: FAMPER, 2018.

GAZZONI, D. L. A sustentabilidade da soja no contexto do agronegócio brasileiro e mundial. Londrina: Embrapa Soja, p. 30, 2013.

MILANEZ, B. Modernização ecológica no Brasil: limites e perspectivas. Desenvolvimento e Meio Ambiente, v. 20, p. 77-89, 2009.

PORTO, M. F.; SOARES, W. L. Modelo de desenvolvimento, agrotóxicos e saúde: um panorama da realidade agrícola brasileira e propostas para uma agenda de pesquisa inovadora. Revista Brasileira de Saúde Ocupacional, v. 37, n. 125, p. 17-50, 2012.

SANTOS, A. J. et al. Viabilidade econômica do sistema agroflorestal grevílea x café na região norte do Paraná. Cerne, v. 6, n.1, p. 89-100, 2000.

SANTOS; I. C.; ARAÚJO, M. F. A reinvenção do cultivo do arroz em Roraima: um legado para a sustentabilidade. In: Encontro Internacional sobre Gestão Empresarial e Meio Ambiente - ENGEMA, 16., 2014, São Paulo, SP. Anais [...] FEA-USP, 2014.

SILVA, M. M. V. da. et al. Dialogando no rádio com agricultores sobre o cuidado com o solo para promover sistemas agroalimentares sustentáveis. Caderno Verde deAgroecologia e Desenvolvimento Sustentável, v. 9, n. 7, p. 6987, 2019. 